\title{
EMViz (Early Music Visualization): MATLAB runtime application
}

\author{
Aaron Carter-Ényì̀ ${ }^{1,2,3,4}$
}

1 Assistant Professor, Morehouse College 2 Instructor, Spelman College 3 Fellow, Fulbright Scholar Program 4 Project Director, Algorithmic Thinking, Analysis and Visualization in Music (ATAVizM)

DOI: 10.21105 /joss.01094

\section{Software}

- Review ¿

- Repository $\boldsymbol{c}^{\boldsymbol{T}}$

- Archive ct

Submitted: 16 October 2018 Published: 20 May 2019

\section{License}

Authors of papers retain copyright and release the work under a Creative Commons Attribution 4.0 International License (CC-BY).

\section{Summary}

EMViz (Early Music Visualization) provides built-in pattern recognition for symbolic music (MIDI) based on a contour recursion algorithm by Carter-Enyi (Carter-Enyi, 2016) producing visualizations of musical form using arc diagrams, as proposed by Wattenberg (Wattenberg, 2002). Currently implemented in MATLAB and deployed as a standalone executable (using MATLAB Runtime), EMViz is now available at emviz.org and https: //github.com/carterenyi/emviz (MIT license).

A primary learning objective in music theory courses is the ability to analyze musical form, often using a bracketed diagram. This humanistic process often involves listening with a score, stopping the recording for a close reading of the score, flipping back and forth through the document to make comparisons, and so on. While manual analysis is important, the conventional method of summarizing one's analysis as a bracket diagram is reductive without being illustrative. A promising digital method for visualization of musical form is found in Martin Wattenberg's Shape of Song, a defunct web app from 2002. The arc diagram visualization technique for Shape of Song is innovative and useful, but ultimately the project did not live up to its potential because of a poor understanding of how composers develop musical themes. Wattenberg describes his string-matching method in his 2002 paper: "Each arc connects two matching passages, where a 'match' means that they contain the same sequence of pitches" (Wattenberg, 2002). However, musical themes and motives are often transposed or otherwise modified in the course of a piece. A concept learned by music majors is the subject and answer of a fugue (an imitative polyphonic composition). The subject is the initial statement of a fugue's theme, stated in a monophonic texture (by itself) and the answer is the first interpolation stated in a polyphonic texture (against counterpoint). Sometimes the answer is an exact transposition (real answer) and sometimes the answer is transposed and modified (tonal answer). In his paper, Wattenberg offers the possibility of matching melodic intervals (instead of pitch-strings), but this too would not match a subject to its tonal answer. So, how do we formalize the relationship between a subject and tonal answer? Or, the improvisational "licks" of Dizzy Gillespie? Such that we could define "themes" as a category that may be formalized computationally? Especially, when a computer does not know where to look for themes or what modifications to expect? Algorithms informed by humanistic understanding of music work much better than those that are not.

There are three primary components of the EMViz MATLAB Runtime application: (1) Data Preparation (Pre-Processing); (2) Pattern Recognition; and (3) Visualization. These components are compared between Shape of Song, EMViz (now available in MATLAB Runtime), and ATAVizM (currently being developed in Python) in Table 1. 


\begin{tabular}{|l|l|l|l|}
\hline & \multicolumn{1}{|c|}{ Shape of Song (2001) } & \multicolumn{1}{c|}{ EMViz (2017) } & \multicolumn{1}{c|}{ ATAVizM (2019) } \\
\hline $\begin{array}{l}\text { Data } \\
\text { Preparation } \\
\text { Method }\end{array}$ & $\begin{array}{l}\text { None (MIDI pitch) } \\
\text { Or some (intervals) }\end{array}$ & $\begin{array}{l}\text { Pitches and/or durations } \\
\text { interpreted as Contour } \\
\text { Levels }\end{array}$ & $\begin{array}{l}\text { Add option of pitch and interval } \\
\text { (to work with similarity } \\
\text { metrics) }\end{array}$ \\
\hline $\begin{array}{l}\text { Pattern } \\
\text { Recognition } \\
\text { Method }\end{array}$ & $\begin{array}{l}\text { Equivalence-based } \\
\text { (string-matching) and } \\
\text { unsupervised }\end{array}$ & $\begin{array}{l}\text { Equivalence-based } \\
\text { (string-matching) and } \\
\text { user supervised (either } \\
\text { input or selection) }\end{array}$ & $\begin{array}{l}\text { Add option of (1) similarity- } \\
\text { based recognition; (2) } \\
\text { algorithm derived from } \\
\text { supervised learning based on } \\
\text { user data }\end{array}$ \\
\hline $\begin{array}{l}\text { Visualization } \\
\text { Method }\end{array}$ & Arcs (monochrome) & $\begin{array}{l}\text { Arcs (color-coded with } \\
\text { legend); Notes (color- } \\
\text { coded by voice)1 }\end{array}$ & $\begin{array}{l}\text { Add option of indicating key } \\
\text { relationships and section } \\
\text { delimiters }\end{array}$ \\
\hline
\end{tabular}

Figure 1: Table of features of Wattenberg's Shape of Song, EMViz (released 2017) and ATAVizM (in development)

The computationally-efficient addition of the contour level data preparation (see CarterEnyi 2016b) (Carter-Enyi, 2016) makes equivalence-based pattern recognition (e.g. stringmatching) much more effective. Notably, this pre-processing of the symbolic data makes significant improvements to performance with negligible added runtime. The contour algorithm behind EMViz and ATAVizM identifies 100\% of the subjects and approximately $80 \%$ of all statements in the 48 Fugues of Bach's Well-Tempered Clavier.

The algorithm brings together contour theory (Morris, 1987), (Quinn, 1997) with studies of melodic accent (Thomassen, 1982), (Huron, 2006). Symbolic music data (.midi, .xml) from various sources (including ELVIS at McGill and the Yale Classical Archives Corpus) may be imported, analyzed and visualized in a matter of minutes. The contour algorithm behind EMViz uses local contour comparisons within a 2-degree radius of each focus pitch. This makes use of Quinn's binary C+ (Contour-Ascent) comparison, where 0 is equal or below and 1 is above the reference pitch (Quinn, 1997). In Figure 1, the subject and tonal answer of Bach's C-minor Fugue (BWV 847) are shown to be equivalent strings using this method (they both produce the same "continuous" matrix).

Example arc diagram visualizations include music from the Liber Usualis, Josquin des Prez and J. S. Bach.

In summary, EMViz (Early Music Visualization) identifies and implements three major improvements over Wattenberg's Shape of Song: (1) a pattern-matching algorithm based on heuristics from music theory, (2) theme identification by user input or selection integrated into the application, and (3) color-coding of arcs (between matched patterns) and a legend to make the diagram more comprehensible, interpretive and utilitarian for research and teaching. Greater accessibility (through Python depoloyment) and enhanced features (referred to in Table 1) will be available with the release of ATAVizM in the near future (https://github.com/carterenyi/atavizm; www.atavizm.org).

\section{Acknowledgements}

The project was funded by the American Council of Learned Societies (ACLS) and the National Endowment for the Humanities (NEH).

\section{References}

Carter-Enyi, A. (2016). Contour Recursion and Auto-Segmentation. Music Theory Online, 22(1). Journal Article. doi:10.30535/mto.22.1.1 


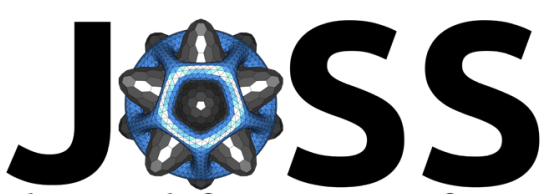

The Journal of Open Source Software

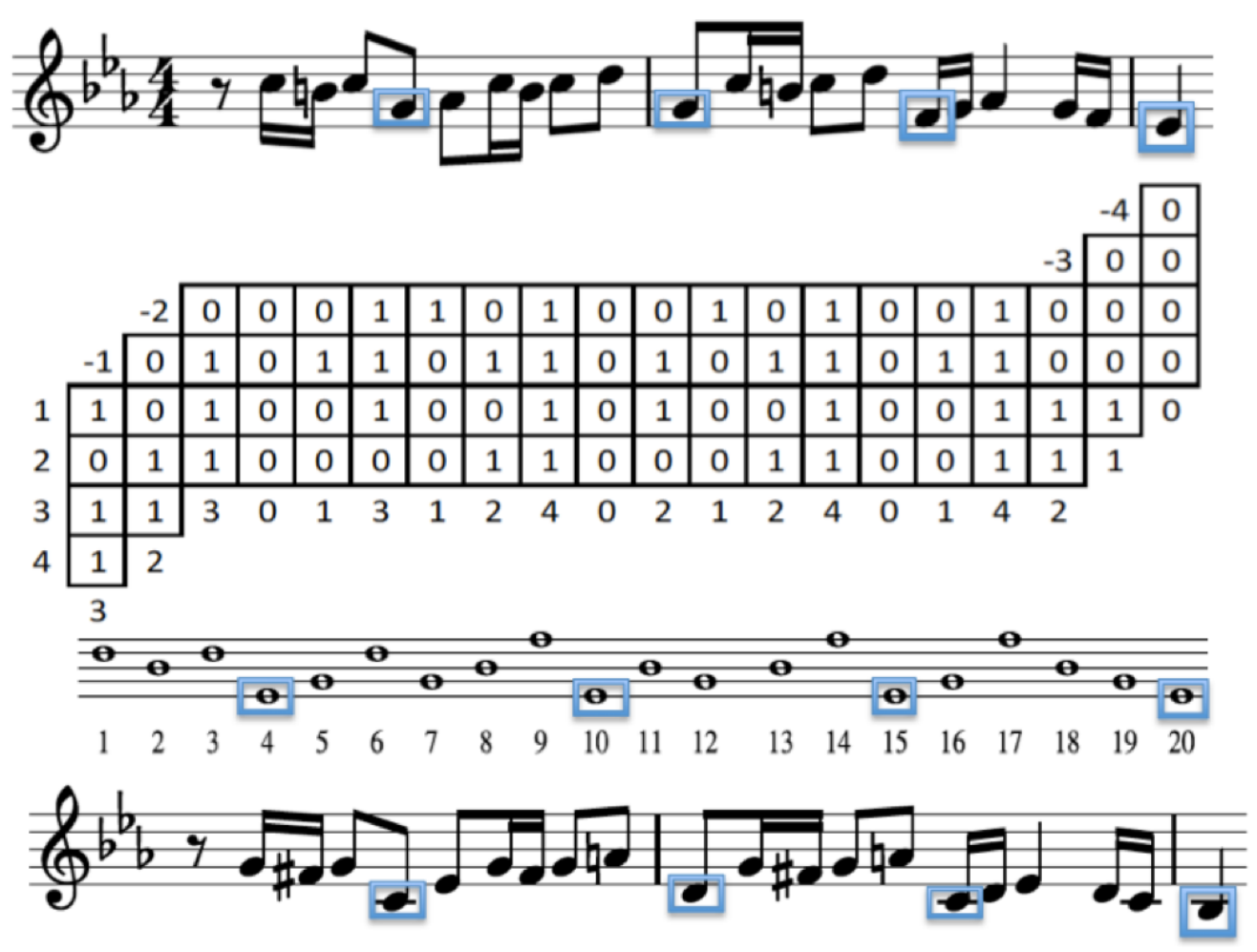

Figure 2: Contour level equivalence between the subject and tonal answer of Bach's Fugue in $\mathrm{C}$ minor BWV 847 based on Carter-Enyi 2016b (Carter-Enyi, 2016)

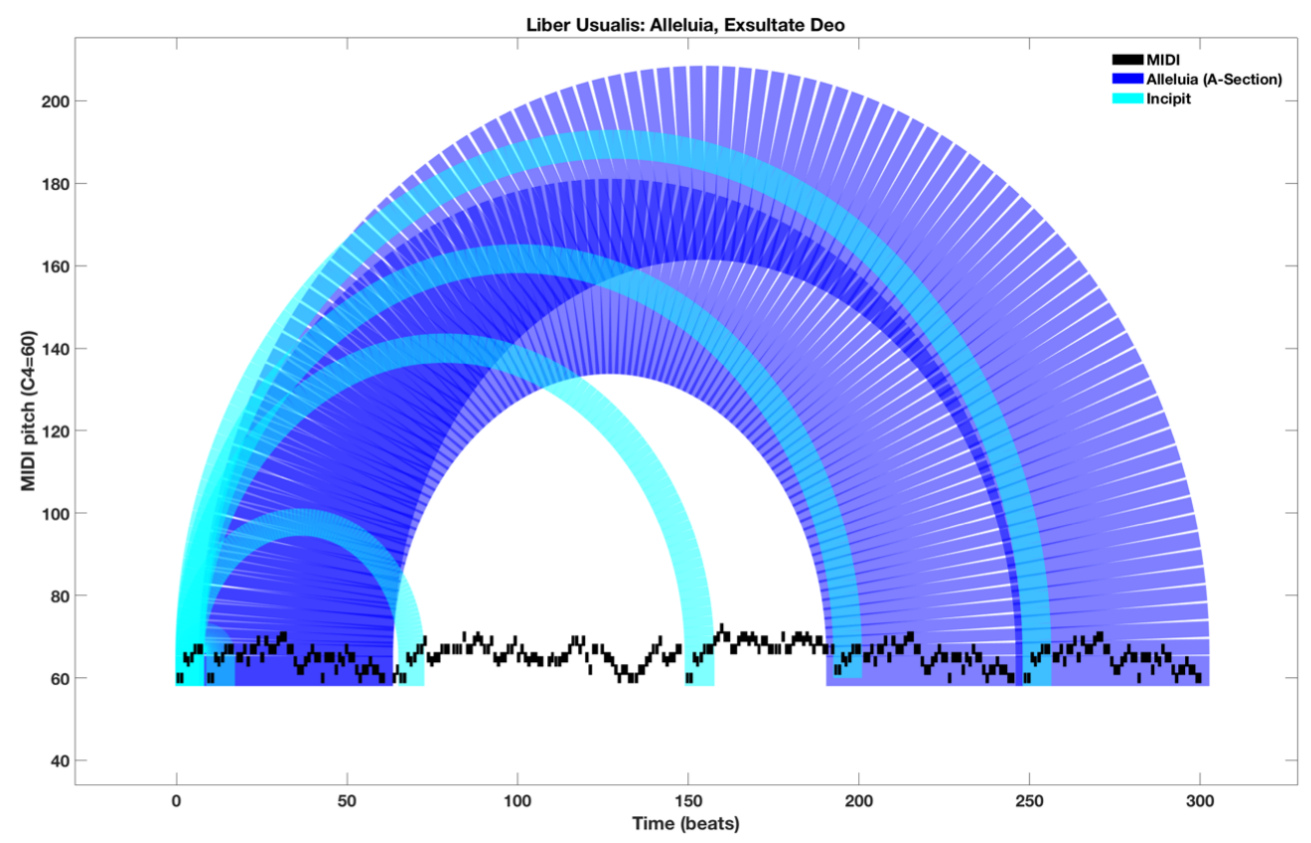

Figure 3: EMViz analysis and visualization of "Alleluia, Exsultate Deo" chant from the Liber Usualis (11th century) 


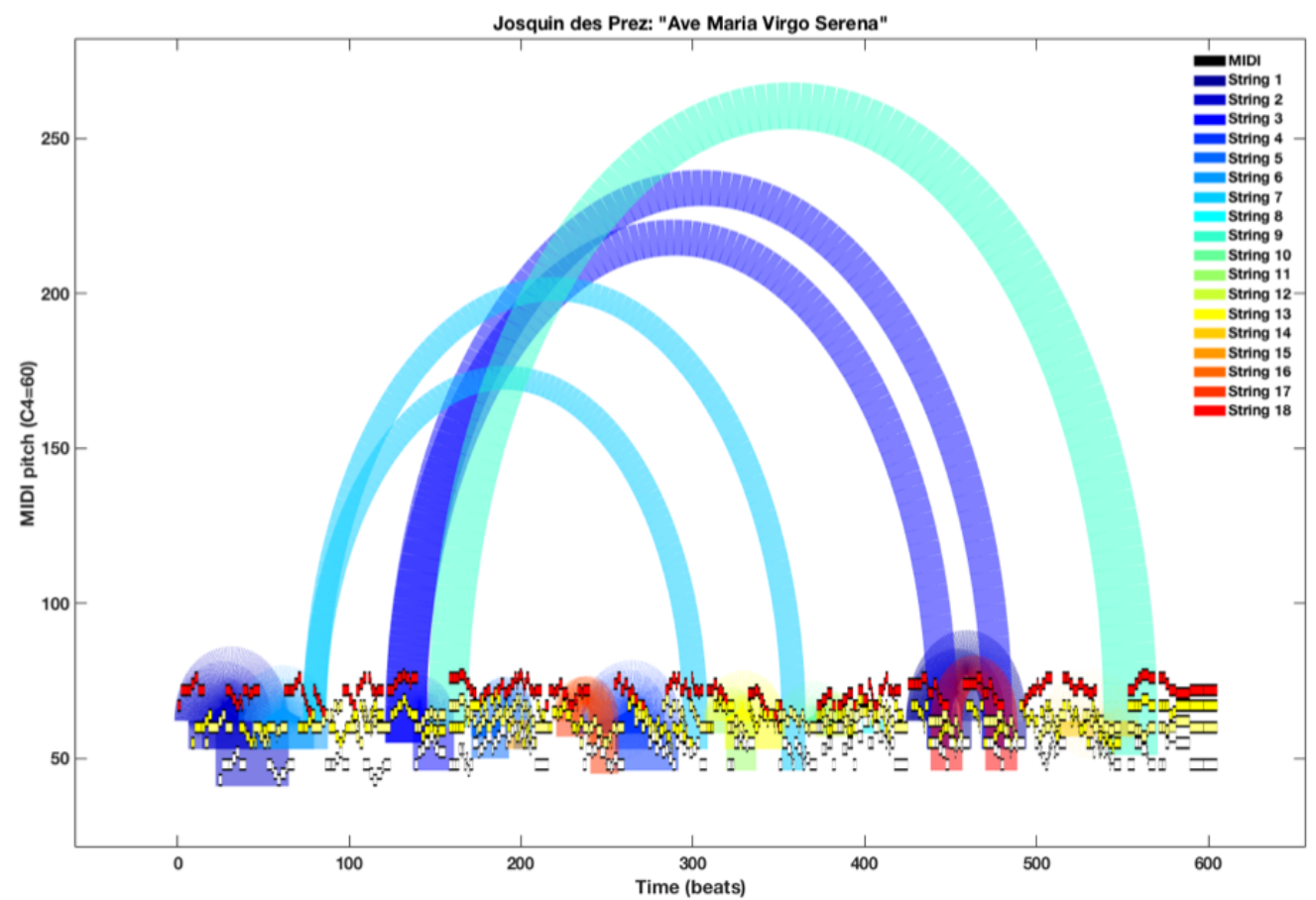

Figure 4: EMViz analysis and visualization of "Ave Maria" by Josquin des Prez (15-16th century)

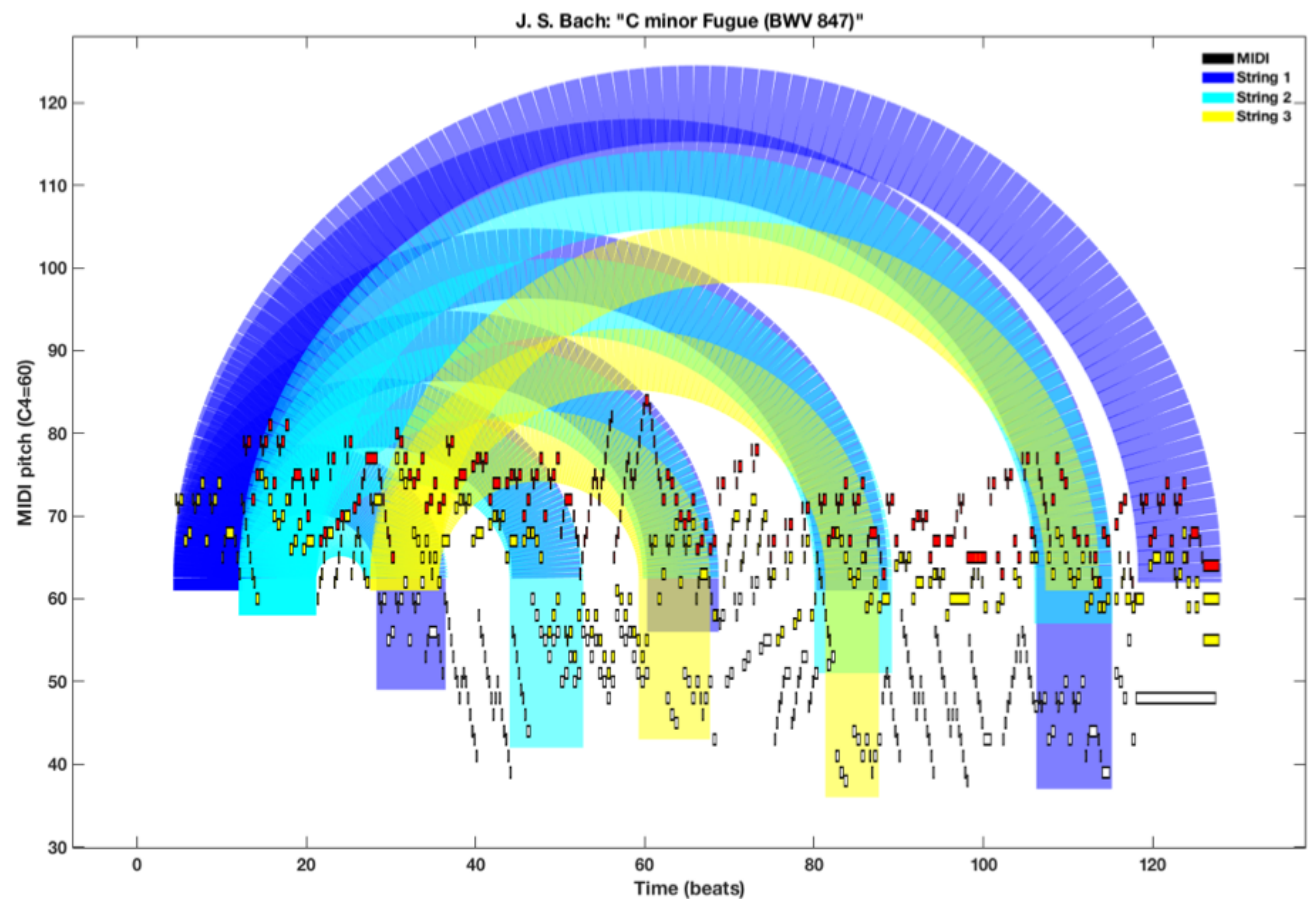

Figure 5: EMViz analysis and visualization of Back's Fugue in C minor BWV 847 (18th century) (NB: an octave displacement is removed from one of the counter-subject 2 statements 
Carter-Enyi, A. (2016). Contour Levels: An Abstraction of Pitch Space based on African Tone Systems (Thesis). Retrieved from http://rave.ohiolink.edu/etdc/view?acc_num= osu1461029477

Huron, D. (2006). Sweet Anticipation: Music and the Psychology of Expectation. Book, Cambridge: MIT Press. doi:10.7551/mitpress/6575.001.0001

Morris, R. D. (1987). Composition with pitch-classes: a theory of compositional design. Book, Yale University Press. doi:10.2307/j.ctt1xp3ss4

Quinn, I. (1997). Fuzzy Extensions to the Theory of Contour. Music Theory Spectrum, 19(2), 232-263. Journal Article. doi:10.2307/745755

Thomassen, J. M. (1982). Melodic accent: Experiments and a tentative model. The Journal of the Acoustical Society of America, 71(6), 1596-1605. Journal Article. doi:10. $1121 / 1.387814$

Wattenberg, M. (2002). Arc diagrams: Visualizing structure in strings. In Information visualization, 2002. INFOVIS 2002. IEEE symposium on (pp. 110-116). Conference Proceedings, IEEE. doi:10.1109/INFVIS.2002.1173155 